Title: Dimensionality and measurement invariance of a brief form of the Young Schema Questionnaire

Running-head: The Brief form of the Young Schema Questionnaire for Adolescents Authors: Laura Santos ${ }^{1}$, Paula Vagos ${ }^{1}$, and Daniel Rijo ${ }^{1}$

${ }^{1}$ Research Unit of the Cognitive-Behavioral Research and Intervention Center, Faculty of Psychology and Educational Sciences, University of Coimbra

Correspondence author: Paula Vagos, Research Unit of the Cognitive-Behavioral Research and Intervention Center, Faculty of Psychology and Education Sciences, University of Coimbra, Rua do Colégio Novo, 3001-802 Coimbra, Portugal

Telephone: 003519651144841

Email: paulavagos@fpce.uc.pt

\title{
Ethical statment
}

Study Funding: This study received no funding; it was part of the unpublished master thesis of the $1^{\text {st }}$ author.

Conflict of Interest: The authors have declared they have no competing or potential conflict of interest.

Author contributions: LS: Designed the study, collected the data, and wrote the introduction and discussion sections of the paper. PV: Analyzed the data, wrote the method and results sections of the paper and collaborated in the editing of the final manuscript. DR: Collaborated with the study design and in the writing and editing of the final manuscript.

Human rights: All procedures performed in this study that involved human participants were in accordance with the ethical standards of the University of Coimbra and with the 1964 Helsinki declaration and its later amendments or comparable ethical standards.

Informed consent: Informed consent was obtained from all individual participants included in the study and, for underage participants, from their parents and/or legal guardians. 


\begin{abstract}
:
The current work aims to develop and examine the psychometric properties of the Brief form of the Young Schema Questionnaire for Adolescents (B-YSQ-A), so that Early Maladaptive Schemas can be accurately measured in younger populations. Early Maladaptive Schemas are self-defeating core themes underlying maladaptive cognition, affect, and behavior. A community sample of 877 adolescents, aged 12 to 18 years old, filled out self-report instruments on maladaptive schemas, anger management, and internalizing and externalizing symptoms.

The items composing the B-YSQ-A were selected based on statistical and content analyses criteria. Its internal structure, reliability, age- and gender-based invariance, and between-gender mean differences were examined, as well as its relationship with external variables. Results indicated a satisfying fit for the 18 original schema factors through confirmatory factor analysis. These schemas also showed adequate internal consistency and test-retest reliability, with the exception of the entitlement/grandiosity schema. The B-YSQ-A was found to be age and gender invariant. Concerning gender differences, boys scored higher on the entitlement/grandiosity, insufficient self-control/discipline, approval/recognition seeking, unrelenting standards/hypercriticalness and punitiveness schemas, whereas girls scored higher on the abandonment/instability, mistrust/abuse, and self-sacrifice schemas. Furthermore, evidence was found for construct validity in relation to measures of internalizing and externalizing symptomatology and of anger expression. Findings offer support for the use of the B-YSQ-A with adolescents, both for research and intervention purposes.
\end{abstract}

Keywords: Early Maladaptive Schemas, Measurement Invariance, Dimensionality, Adolescents, Young Schema Questionnaire (YSQ) 
Early Maladaptive Schemas (EMSs) constitute a major theoretical feature of Schema Therapy (ST; Young, 1999). They are defined as pervasive, inflexible and dysfunctional to a significant degree, and may, when triggered, cause disruptive emotional states and associated maladaptive behaviors. EMSs have been found to associate with the onset and maintenance of psychopathology (Young, Klosko \& Weishar, 2003), including depressive and anxious symptoms (Welburn, Coristina, Dagg, Pontefract, \& Jordan, 2002), eating disorders (Waller, Meyer \& Ohanian, 2001), alcohol-dependence (Shorey, Anderson, \& Stuart, 2012), and personality disorders (Bach, Simonsen, Chrustoffersen \& Kriston, 2015). EMSs develop early in life as a result of the interaction between the child's temperament and adverse early experiences with caregivers. When basic developmental needs are not met in a satisfactory way, the child's functioning in different life domains can become clearly impaired. EMSs are highly resistant to change, given that they continue to be elaborated throughout one's lifetime (Young, 1999). The ST framework has proposed eighteen schemas grouped into five schema domains that correspond to core emotional needs that remained unmet throughout childhood (Young et al., 2003; cf. Supplementary material 1).

The Young Schema Questionnaire (YSQ) was developed to assess EMSs. Over the last years, three version have been proposed (i.e., the Young Schema Questionnaire Long Form YSQ-LF, with 205 items addressing 16 schemas, Young \& Brown, 1990; the Young Schema Questionnaire Short - YSQ-S with 75 items addressing 15 schemas, Young, 1999; and the YSQ-S3, consisting of 90 items evaluating 18 EMSs; Young, 2005). The most recent version, the YSQ-S3, has been extensively researched. Specifically, the 18 EMSs factor structure has received considerable support (Calvete, Orue \& González-Diez, 2013; Rijo, 2009), although some EMSs revealed low reliability (e.g. entitlement/grandiosity, Bach et al., 2015; Hawke \& Provencher, 2012; Kriston, Schäfer, Jacob, Härter, \& Hözel, 2013; and dependence/incompetence, Calvete, Orue \& González-Diez, 2013). Concerning schema domains, which have been tested as higher order factors, some studies corroborated the 5 proposed domains, while others found evidence for only 3 domains (Rijo, 2009; Soygüt, 
Karaosmanoglu, \& Cakir, 2009), and yet others found no evidence for schema domains (Hawke, \& Provencher, 2012; Kriston, Schäfer, Jacob, Härter, \& Hözel, 2012).

Despite the relevance of the development of EMSs during childhood and their further elaboration throughout adolescence, and regardless of the impact of these EMSs on later psychopathology (Young et al., 2003), research carried out with children and adolescents has been scarce, in comparison with research with adult samples (Van Vlierberghe, Braet, Bosmans, Rossel, \& Bogels, 2010). Nevertheless, it is essential to assess these variables in adolescence in an accurate manner in order to determine the early presence of EMSs and test for their stability over time (Rijkeboer \& Boo, 2010; Stallard, 2007). Hence, and based on previous findings validating the YSQ with adults, it would be useful to develop a shorter and developmentally appropriate measure of EMSs for adolescents, in order to overcome their tendency to become burdened, tired and disengaged with long self-report instruments (Fan et al., 2006).

Some studies have been conducted with this purpose in mind, in which the items were rephrased with the goal of becoming more meaningful to children (Rijkeboer \& Boo, 2010) or to adolescents (Muris, 2006; Van Vlierberghe et al., 2010). Most of these studies have been conducted with the YSQ-S, which assesses 15 schemas, instead of the 18 EMSs currently proposed. Moreover, findings have not been unanimous and some have even been controversial (Muris, 2006; Rijkeboer \& Boo, 2010; Saritaş \& Gençöz, 2011; Stallard \& Rayner, 2005; Van Vlierberghe et al., 2010). Specifically, the following issues can be pointed out: 1) the length of the questionnaires ranges from 15 items, one for each EMS (Stallard \& Rayner, 2005), to 75 items (Rijkeboer \& Boo, 2010; Van Vlierberghe et al., 2010); 2) factors vary from completely agreeing with the proposed schemas (Van Vlierberghe et al., 2010), to extracting only 10 (Simons \& Free, 2000), or confirming only 8 schemas (Rijkeboer \& Boo, 2010); 3) evidence regarding schema domains has either confirmed five higher-order factors/ schema domains (Van Vlierberghe et al., 2010), or extracted 3 (Muris, 2006; Saritaş \& Gençöz, 2011) or 4 schema domains (Stallard, 2007). 
Only the Saritaş and Gençöz study (2011), conducted with a non-clinical sample of 356 adolescents aged between 15 and 18 years old, analyzed the most recent and updated version of the YSQ (i.e., YSQ-S3). By using the predefined EMSs as observable variables in an exploratory factor analysis (i.e., they did not consider a priori the loading of individual items on each EMSs but rather used the sum of scores for each EMSs to test for the presence of schema domains), this study found evidence for 3 schema domains, which were named "Impaired limits-exaggerated standards", "Disconnection-rejection", and "Impaired autonomy-other directedness". They also found that the "Impaired limits-exaggerated standards" domain had a significant association with anger, whereas the "Disconnection-rejection" and "Impaired autonomy-other directedness" domains had significant associations with anxiety.

Regarding the EMSs construct validity, and despite the use of earlier versions of the YSQ, previous results showed that most EMSs associated with both internalizing and externalizing problems (Van Vlierberghe et al., 2010). While social isolation/alienation and vulnerability to harm/illness EMSs were highly predictive of internalizing symptoms, the grandiosity/entitlement and dependence/incompetence EMSs were predictors of externalizing symptoms (Van Vlierberghe \& Braet, 2007). Also, EMSs in general seemed to be positively associated with negative affectivity and aggressive mood (with exception of the self-sacrifice and enmeshment schemas; Rijkeboer \& Boo, 2010). Moreover, specific EMSs such as failure, submission, and insufficient self-control were negatively associated self-regulatory capacities (i.e., effortful control; Rijkeboer \& Boo, 2010).

Only a few studies explored gender differences in EMS within adolescence, and findings were contradictory. Namely, whereas a study using the YSQ-LF found no differences between gender (González-Jiménez \& Hernández-Romera, 2014), another found that adolescent girls scored higher on EMSs than boys (Calvete, Orue \& Hankin, 2015), particularly on those schemas referring to the other-directedness domain, which, in turn, have been associated with higher levels of social anxiety (Calvete, Orue \& Hankin, 2013). Gender-based findings on EMSs in adolescence may benefit from additional consideration, namely from the perspective of measurement invariance analyses, which would allow for more accurate comparisons. 
With the exception of the Saritaş and Gençöz study (2011), most of the instruments available for use with younger populations do not assess the current proposal of 18 EMSs and different findings concerning the EMSs and their domains have been reported. On the other hand, the YSQ-S or the YSQ-S3 are still frequently used, even if they are extensive questionnaires using a language that is not completely appropriate for the specificities of adolescents (e.g. González-Jiménez \& Hernández-Romera, 2014). Furthermore, adolescence itself includes several phases characterized by fairly distinctive physical, cognitive, social and emotional development features (Sawyer et al., 2012). Hence, the development of a short form of the YSQ-S3, suitable for assessing schemas in adolescents continues to be relevant, especially within the most recent theoretical framework of 18 EMSs. The development of this instrument should be useful in research on the nature and development of maladaptive cognitive patterns in children and adolescents (Muris, 2006). Such instrument may also be useful in the assessment of the efficacy of interventions targeting dysfunctional cognitive patterns that are supposed to be more responsive to change within this age range (Stallard \& Rayner, 2005).

The current work validates a brief version of the YSQ-S3 adapted for adolescents - the Brief form of the Young Schema Questionnaire for Adolescents (B-YSQ-A). Specifically its internal structure, internal consistency, age- and gender-based measurement invariance, between-gender mean comparisons, and association with external variables were investigated. The 18 EMSs measurement model was expected as a good fit for the data; good internal consistency values for all EMSs were also expected. In turn, it was expected that including schema domains would not improve the model's fit. The B-YSQ-A was further expected to be age and gender invariant, and girls were expected to score higher on EMSs in comparison with boys, particularly on those EMSs associated with internalizing psychopathology. Finally, EMSs as assessed through the B-YSQ-A were expected to be positively associated with both internalizing and externalizing problems and with dysfunctional anger expression.

\section{Method}

\section{Participants}


The participants were 877 adolescent boys $(n=389)$ and girls $(n=488)$, aged between 12 and 18 years old, who filled out the B-YSQ-A (see Instruments section). This age range, though extensive, falls within the age limits of adolescence, including the early (i.e., 12 to 14 years old, $n=407,45.7 \%$ of the sample) and late phases (i.e., 15 to 18 years old, $n=476$, $54.3 \%$ of the sample) of adolescence (Swayer et al., 2012). Concerning academic performance, participants attended the $5^{\text {th }}$ through the $12^{\text {th }}$ grade and had had between 0 and 3 school holdbacks (i.e., being retained in the same school year due to academic failure). As for socioeconomic status (SES), the majority of the sample belonged to a low SES (cf. Table 1)

\section{[Insert Table 1]}

Boys were significantly older than girls $(t(875)=2.43, p=.015$; for boys $\mathrm{M}=15.01$, $\mathrm{SD}=1.89$ and for girls $\mathrm{M}=14.70, \mathrm{SD}=1.83$ ). Also, boys had, on average, experienced more school holdbacks $(t(708.80)=3.57, p<.001$; for boys $\mathrm{M}=.34, \mathrm{SD}=.65$ and for girls $\mathrm{M}=.20$, $\mathrm{SD}=.49$ ). Alternatively, boys and girls had, on average, completed the same number of school years $(t(875)=1.49, p=.14 ;$ for boys $\mathrm{M}=8.39, \mathrm{SD}=1.69$ and for girls $\mathrm{M}=8.22, \mathrm{SD}=1.69)$ and were similarly distributed by SES $\left(\chi^{2}(2)=3.22, p=.20\right)$.

A subsample of 146 participants (i.e., validity subsample) was randomly selected to fill out the instruments assessing relevant external variables (i.e., Youth Self-Report and State Trait Anger Expression Inventory; see Instruments section). The comparison between participants included and not included in this subsample (cf. Table 1) showed a random distribution by gender $\left(\chi^{2}(1)=.05, p=.82\right)$ and SES $\left(\chi^{2}(2)=1.21, p=.55\right)$. Alternatively, participants in this subsample were significantly older $(t(213.34)=6.18, p<.001)$, and, on average, had completed more school years $(t(229.32)=5.43, p<.001)$ and had had more school holdbacks $(t(188.81)=$ $2.61, p=.010)$.

Another subsample within the complete sample filled out the B-YSQ-A 3 to 4 weeks after the first data collection (i.e., stability subsample; cf. Table 1). The results of the comparison between participants included and not included in this subsample showed that participants were evenly distributed by gender $\left(\chi^{2}(1)=.09, p=.77\right)$ and SES $\left(\chi^{2}(2)=.63, p=\right.$ $.73)$; they also had had, on average, a similar number of school holdbacks ( $\mathrm{t}(875)=-.53, \mathrm{p}=$ 
59). Furthermore, participants in this subsample were significantly older $(t(81.35)=18.94, p<$ $.001)$ and had, on average, a completed more school years $(t(114.93)=27.56, p<.001)$.

\section{Procedure}

Seven schools located in the Center region of Portugal were conveniently selected, after the national ethics committee and the direction boards of the schools had approved the study. Of the initial seven schools, two were randomly selected, one to be used as the validity sample, and other to be used as the stability sample. Therefore, in five schools students were asked to fill out only the YSQ-S3, in one school students were asked to fill out the YSQ-S3 and the validity measures (see instrument section), and in another school students were asked to fill out the YSQ-S3 in two different moments in time. In order to minimize the interference of the data collection on the academic activities, schools themselves selected the classes that would be invited to take part in the study. They were asked not to select classes that were distinctive in any particular way (e.g., lower or higher academic achievement) from the typical classes of that school. Therefore, not all of the students enrolled in each school were invited to take part in this research (in fact, schools often selected only one class per school year).

In addition to institutional authorizations and ethical considerations, parents/legal guardians also gave informed consent for their underage children (i.e., younger than 18 years of age) to participate in the study; participants who were 18 years old gave their own consent. Students who were selected by the schools as potential participants were asked to voluntary participate and were informed about the goals of the study. The anonymity and confidentiality of their responses were guaranteed and they were also assured that they could withdraw from the study at any time. To preserve the anonymity of families and of 18-year-old students, the schools did not provide the research team with information on the students who were not selected to participate in this study nor on those who declined to collaborate. Data was collected in group during classes, in the presence of a researcher, to ensure confidential and independent responses, and to answer any possible questions.

\section{Measures}


Young Schema Questionnaire - S3 (YSQ-S3, Young, 2005; Portuguese version by Pinto Gouveia, Rijo, \& Salvador, unpublished).

The YSQ-S3 is a 90-item self-report questionnaire that assesses the 18 EMSs proposed by Young et al. (2003). Each item is answered using a 6-point Likert scale rated from 1 (completely untrue of me) to 6 (describes me perfectly). Higher scores indicate a stronger presence of an EMS. The YSQ-S3 was validated for the Portuguese population in a sample of 1226 adults from the general population. The 18 -factor structure was confirmed with an acceptable goodness of fit, after removing 6 items from the original 90. Both the total scale and each factor revealed good internal consistency values, except for the unrelenting standards/hyper-criticalness EMS, which presented alpha values lower than .60. The YSQ-S3 also showed an adequate concurrent validity in relation to depression and psychopathology in general, discriminant sensitivity between clinical groups with DSM IV TR Axis I and Axis II disorders and non-clinical groups, and good stability over time (Rijo, 2009; Rijo, 2017).

The Young Schema Questionnaire for Adolescents (YSQ-A) resulted from simplifying, rephrasing, and adapting the 90-item Portuguese version of the YSQ-S3, as well as its rating scale, so that adolescents might more easily understand the items and answer them. For example, the item "Most other people are more capable than I am in areas of work and achievement" from the adult version was rephrased to "Most people have more skills than me at school". The rating scale was also adapted, so that it referred to daily rather than introspective experiences. So, it ranges from 1 (It has nothing to do with what happens or happened to me) to 6 (This is exactly what happens or happened to me). Information on the procedures that lead to the development of the B-YSQ-A and on its psychometric properties is presented in the results section.

Youth Self Report (YSR. Achenbach, 1991; Portuguese version by Fonseca \& Monteiro, 1999).

The YSR is a self-report survey aiming to assess emotional and behavioral problems in adolescents. The present study used the second part of this instrument composed by 119 items, 103 of which are related to specific behavioral problems and 16 relate to socially desirable 
behaviors. Each item is rated on a Likert scale ranging from 0 (not true) to 2 (often true). The Portuguese version assesses internalizing and externalizing problems, which are divided into 6 factors (i.e., withdrawn, somatic complaints, anxiety and depression, thought problems, attention problems/hyperactivity, and anti-social behavior). Its internal consistency values varied between .70 and .80 (Fonseca \& Monteiro, 1999). For parsimony reasons, only the externalizing and internalizing clusters were used in the current work to examine the construct validity of the B-YSQ-A. They showed very good internal consistency values within the current sample: $\alpha=.86$ for externalizing and $\alpha=.84$ for internalizing problems.

State Trait Anger Expression Inventory (STAXI, Spielberger, 1988; Portuguese version by Silva, Campos and Prazeres, 1999).

The STAXI is a 44-item self-report instrument intended to assess the intensity of experienced anger and anger expression. It includes three parts measuring state anger, trait anger, and anger expression. Trait anger is computed from two subscales (i.e., temperament and reaction); anger expression includes exteriorized anger, internalized anger and anger control. Each item is rated on a Likert-scale ranging from 1 (not at all to me) to 4 (almost always). STAXI's original version presented 6 factors and good internal consistency scores, varying from .73 to .93 (Spielberger, 1988). In the Portuguese validation study, the same factors were replicated and internal consistency values varied from .65 to .88 ; only trait anger showed low reliability ( $\alpha=.65$; Silva, Campos $\&$ Prazeres, 1999). Again for parsimony reasons, only the state anger, trait anger, and anger expression measures were used in the current work to investigate construct validity. Within the current sample, their internal consistency values were: $\alpha=.92$ for state anger, $\alpha=.86$ for trait anger, and $\alpha=.67$ for anger expression.

\section{Data Analyses}

Statistical analyses were undertaken using the IBM SPSS Statistics 21, the R software (RStudio Team, 2015), and the Mplus v7.4 (Muthén, \& Muthén, 2012). Mplus v7.4 was used for Confirmatory Factor Analysis (CFA) and multi-group analyses. The 90 items of the YSQ-S3 were initially analyzed. Three non-nested measurement models were tested via CFA: 1) a onefactor model, assuming an underlying total factor for the YSQ-S3; 2) a 18-factor model, which 
organizes the 90 items into 18 EMSs; and 3) a 18 first order factors further organized into 5 higher order factors, assuming that the 18 EMSs are proposed as being organized into 5 schema domains. The fit of these models was assessed taking into account the guidelines provided by Hu and Bentler (1999), namely a Standardized Root Mean Square Residual (SRMR) $\leq .09$ combined with either a Comparative Fit Index (CFI) $\geq .95$ or a Root Mean Square Error of Approximation $(\mathrm{RMSEA}) \leq .06$. Moreover, the non-nested measurement models were compared considering that better fit is showed by lower values for the SRMR, the RMSEA and the Akaike Information Criteria (AIC) and by higher values of CFI.

The IBM SPSS Statistics 21 was then used for inter-item and item-total correlation analyses. These analyses were carried out using the model that was found to best fit the data out of the three competing models under study for the complete YSQ-S3 (see above) and their results served as criteria for selecting items to be included in the B-YSQ-A. Three items were selected as representatives for each of the 18 EMSs, based on the following criteria: 1) higher mean inter-item and corrected item-total correlation with the items pertaining to each schema, 2) higher loading values within the best fitting measurement model, and 3) lowest impact on decreasing the internal consistency value of each schema. Items achieving the highest number of criteria were proposed to be kept. This first selection of items to be kept or to be excluded was presented to three experts in schema focused theory and therapy with adolescents, who were asked to judge if the items selected to be excluded portrayed essential contents of the intended schema. The final 54 items of the B-YSQ-A were selected through a combination of the statistical criteria with the experts' perspectives, and were then subjected to CFA analyses on the three previously defined internal measurement models.

The best fitting measurement model for the B-YSQ-A was further tested for age- and gender-based invariance using Mplus v.7.4. At least partial scalar invariance is advisable if multi-group comparisons are to be considered valid. Configural, metric, and scalar invariance were sequentially tested, which meant that the measurement model was freely estimated in both groups, then loadings were fixed to be equal across groups, and then intercepts were also constrained to be equal across groups (Chen, 2007). According to Chen (2007), metric 
measurement invariance is determined when $\Delta \mathrm{CFI} \leq-.01$ combines with $\triangle \mathrm{RMSEA} \leq .015$ or with $\triangle \mathrm{SRMR} \leq .03$ and scalar invariance is established when $\Delta \mathrm{CFI} \leq-.01$ combines with $\Delta$ RMSEA $\leq .015$ or with $\triangle \mathrm{SRMR} \leq .01$. Having achieved measurement invariance, a latent mean comparison approach was used for the comparison of the mean scores of boys and girls (Dimitrov, 2006).

Further correlation analyses concerning the validity of the results of the B-YSQ-A in relation to external variables (i.e., STAXI and YSR) were undertaken, in addition to temporal stability analyses, both using the IBM SPSS Statistics 21. Internal consistency was also considered, based on the ordinal version of the Guttman indicator, given the ordinal nature of the data of the current study and the fact that it was severely asymmetrical (see below; Gaderman, Guhn, \& Zumbo, 2012); values higher than .70 were considered acceptable for research/ data gathering purposes. Internal consistency analyses were carried out using the R.

\section{Results}

In order to decide on the appropriate estimator for the CFA and multi-group analyses, Mardia's Test of multivariate normality was computed. Results indicated that data taken from the 877 participants were not multivariate normal $\left(\chi^{2}\right.$ skewness $(1721.70)=25655.5, p<.001$; $\chi^{2}$ kurtosis $\left.(10336.26)=236.30, p<.001\right)$. So, and considering that the response scale used six ordinal points, the Maximum Likelihood Robust estimator was used for all CFA and multigroup analyses, given that is has performed well with non-normal ordinal data ( $\mathrm{Li}, 2016)$.

\section{Item selection for the B-YSQ-A}

All of the alternative models applied to the 90 items composing the complete form of the YSQ-S3 achieved acceptable fit indicators based on the RMSEA and SRMR combination, although the CFI values were relatively low. All of the three fit indicators obtained for the second model, which considered the 18 schemas as first order factors, were somewhat better, and so this was chosen as the best fitting model (cf. Table 2). Loading values were always significant $(p<.001)$ and higher than .437 , with the exception of item 63 (i.e., I often feel as if my parent(s) is(are) living through me - that I don't have a life of my own), which had a nonsignificant loading value of .071 $(p=.118)$ on the enmeshment/undeveloped self EMS. 


\section{[Insert Table 2]}

Supplementary material 2 displays the mean inter-item and item-total corrected correlation values found for the five items composing each schema, in addition to the internal consistency value of each schema if one item was removed. It was decided that the three items within those five that fulfilled the most of the inclusion criteria would be included in the first version of the B-YSQ-A (see statistical procedures section), which was then subjected to expert analyses. Two experts believed that essential contents were missing by excluding the two nonselected items from the mistrust/abuse and social isolation/alienation schemas; the third expert thought that all relevant contents were addressed by the items that the research team wished to keep in this brief from. Upon considering both the major ideas behind each schema (see Supplementary Material 1) and the statistical criteria underlying the suggestions made by the experts on the items to be kept, item 76 was used instead of the initially proposed item 40 to measure social isolation/alienation. For the remaining schemas, the initially proposed items were kept given that: 1) no consensus was achieved between experts, 2) the items seemed in line with the theoretical model, and 3) the statistical criteria showed an evident difference between items to be kept and items to be excluded. The B-YSQ-A was thus composed of 54 items and each of the 18 EMSs was assessed through three items.

It was further tested if there were time gains when filling in the B-YSQ-A (i.e., 54 items) in comparison with the YSQ-S3 (i.e., 90 items). Using a convenience sample of 8 adolescents (5 boys; $62.5 \%$ ) not included the samples described above aged 13 to 16 years old $(\mathrm{M}=14.13 ; \mathrm{DP}=1.36)$, a significant difference was found $(z=-2.52, p=.012)$ in time needed to fill out the YSQ-S3 (i.e., roughly 13 minutes) and the B-YSQ-A (i.e., roughly 7 minutes).

\section{Brief form of the Young Schema Questionnaire for Adolescents (B-YSQ-A) Internal structure and consistency}

The 18-factor measurement model fitted best to the data (cf. Table 2). Loading values were always significant $(p<.001)$ and higher than .518 (cf. Table 3). Also, by retaining $60 \%$ of the items in each measure (i.e., 3 out of 5 items), each 3 -item measure retained at least $77 \%$ of the variance explained by their 5-item counterpart (cf. Table 3). 


\section{[Insert Table 3]}

Two out of 18 EMSs fell below the cut-off value for internal consistency (i.e., entitlement/grandiosity and self-sacrifice; cf. Table 4). Spearman correlation values between the scores from each measure at times 1 and 2 were always significant $(p<.001)$ and of moderate or strong magnitude, ranging from $r_{\mathrm{s}}=441$ for emotional deprivation to $r_{\mathrm{s}}=.774$ for negativity/pessimism (cf. Table 4).

\section{[Insert Table 4]}

\section{Measurement invariance and descriptive analyses}

The 18-factor measurement model achieved acceptable RMSEA and SRMR values for both the early and late adolescent samples and for both the male and female samples (cf. Table 2). Moreover, all loading values were significant at $p<.001$ for both samples. Concerning age, loading values were higher than .429 for early adolescents and .526 for late adolescents (in both cases for item 11, I'm the one who usually ends up taking care of the people I'm close to). As for gender, loading values were higher than .455 for boys (i.e., item 11) and higher than .376 for girls (i.e., item 68, I feel that I shouldn't have to follow the normal rules and conventions that other people do; cf. Table 3). Age and gender configural invariance was thus determined. Full metric $(\Delta \mathrm{CFI}=.001, \Delta \mathrm{RMSEA}=-.001 ; \Delta \mathrm{SRMR}=.000$ for age and $\Delta \mathrm{CFI}=-.003, \Delta \mathrm{RMSEA}=$ $.001 ; \Delta \mathrm{SRMR}=-.001$ for gender $)$ and full scalar invariance $(\Delta \mathrm{CFI}=-.003, \Delta \mathrm{RMSEA}=.000$; $\Delta \mathrm{SRMR}=.000$ for age and $\Delta \mathrm{CFI}=-.007, \Delta \mathrm{RMSEA}=.001 ; \Delta \mathrm{SRMR}=.001$ for gender) were sequentially, established concerning both age and gender (see procedures section on the successive constraints associated with each type of invariance).

Latent mean comparison analyses showed that boys scored significantly higher than girls on the entitlement/grandiosity, insufficient self-control/discipline, approval/recognition seeking, unrelenting standards/hyper-criticalness, and punitiveness schemas. Girls, in turn, scored significantly higher than boys on abandonment/instability, mistrust/abuse, and selfsacrifice. These latent means parallel the descriptive values presented in Table 4, which were calculated as the sum of the responses of each participant to the three items composing each measure (cf. Table 4). Because boys were significantly older than girls (see Participants 
section), ANCOVAS for between-gender differences were also computed, having age as a covariate; between-gender differences remained stable after controlling for age.

\section{Validity in relation to external variables}

The correlation values obtained between the EMSs and the internalizing and externalizing dimensions of the YSR are presented in Table 5. The internalizing cluster was positively and moderately correlated with most of the EMSs, indicating that higher values in internalizing symptoms associate with higher values in EMSs. The highest correlation value for internalizing symptoms was observed in relation to the social isolation schema. Concerning the externalizing dimension of the YSR, overall, higher symptomatology was associated with increased scores in the EMSs. The highest correlation value was found in relation to the entitlement/grandiosity schema.

\section{[Insert Table 5]}

Positive and significant correlation values were also found between the three measures of the STAXI and the majority of the 18 schemas (cf. Table 5), meaning that higher levels of trait anger, state anger and anger expression associated with higher levels of EMSs. The highest correlation value for state anger and for anger expression was found in relation to the mistrust/abuse schema, whereas trait anger correlated the highest with entitlement/grandiosity. The correlation values found for trait anger in relation with schemas were generally higher than those found for state anger and anger expression.

\section{Discussion}

Adolescence is an in-between stage of development, in which the pillars for relevant schemas are already set but not entirely solidified, making their change easier, either via therapy and/or intra and interpersonal positive life experiences (Young et al., 2003). Thus, it seems relevant to develop appropriate ways of assessing the presence and prominence of EMSs, which, according to Stallard and Rayner (2005), are useful for the definition and adoption of the proper preventive or curative intervention strategies. Previous studies attempting to establish an appropriate method to do so have come to conflicting findings (Rijkeboer \& Boo, 2010; Saritaş \& Gençöz, 2011; Van Vlierberghe et al., 2010). In trying to overcome, at least partially, 
limitations found in existing research, this study examined the psychometric properties of a new, shorter, and language-appropriate measure of EMSs in adolescence, based on a large community adolescent sample. In relation to previous efforts in measuring schemas in younger samples, the B-YSQ-A holds the advantages of having a stable and acceptable number of items across schemas and of assessing all 18 theoretically proposed schemas using a limited number of items and, consequently, of time spent.

By combining statistical and content analyses criteria, 54 items were selected from the YSQ-S3 (i.e., 90 items) to compose the B-YSQ-A. This selection allowed each EMS to be assessed by three items. Confirmatory factor analyses indicated that the selected items reflected the theoretically proposed 18 EMSs (Young, 1999), while previous works referring to the 18 EMSs with adolescents focused solely on the higher-order constructs (i.e., schema domains; Saritaş \& Gençöz, 2011). Moreover, the B-YSQ-A was found to be a valid tool for assessing the 18 EMSs across the age span of 12 to 18 years old.

One further attempt was made to organize the 18 EMSs into the 5 theoretically defined schema domains. Though it also achieved statistical fit, the fit indicators were, nonetheless, worse, in comparison to considering only the 18 correlated schemas. Inconsistent results concerning schema domains have been found in several other studies with adults (Hoffart et al., 2005; Kriston et al., 2012; Welburn et al., 2002) and adolescents (Muris, 2006; Saritaş \& Gençöz, 2011). Nevertheless, the present study supports that EMSs can be organized into the suggested domains, even if it was not the best fitting model. Theoretically, these findings suggest that schema domains should not be seen as hierarchically superior factors in relation to schemas, as it is conceptualized in CFA analyses. Alternatively, a bifactorial approach to these constructs may be well suited; by doing so, Kriston et al. (2012), in fact, found evidence for the acceptability of schema domains in an adult sample.

Concerning internal consistency, most of the dimensions corresponding to the 18 EMSs achieved good reliability values. A minority of them achieved internal consistency values lower than (though very close to) .70 (i.e., entitlement/grandiosity and self-sacrifice). About the entitlement/grandiosity schema in particular, it had not performed well in other studies with 
adults (Bach et al., 2015; Kriston et al., 2013). The temporal stability of the measures was moderate. Schemas in adolescence may be particularly shifting, and so evaluating them is subjected to higher diversity in the experience of each schema (i.e., internal consistency of each measure) and across time (i.e., test-retest validity).

Schema development occurs alongside the challenges of adolescence. Consequently, it seems reasonable that some schemas could be prone to higher inconsistency, particularly those which are not yet considered maladaptive within this age group because their content mirrors normative developmental tasks (Rijkeboer \& Boo, 2010). As such, it may be understandable that the enmeshment/undeveloped self schema did not associate significantly with internalizing problems, externalizing problems or anger, because it may be an expected and normative experience in adolescence, thus not associated with maladaptive constructs. The same reasoning applies to the abandonment/instability schema (i.e., thinking of relationships as unstable); relationships are, in fact, ever changing in adolescence and, therefore, do not associate necessarily with negative psychological constructs. Additionally, the overall means on the majority of EMSs were low in the current sample, which may be related with the non-clinical nature of the sample; in fact, previous research with non-clinical samples also found low overall means for EMSs (Van Vlierberghe et al., 2010).

The 18 schemas measurement model proved to be invariant across gender, thus allowing for valid comparisons between male and female adolescents (Chen, 2007). Boys and girls have been suggested to present diverse levels of risk for psychopathology based on observable symptoms (i.e., diagnostic criteria), with girls being more prone to depressive and anxious problems (Calvete et al., 2015) and boys more prone to oppositional and conduct problems (Maughan et al., 2004). These observable differences should find their equivalent in the favoring of maladaptive schemas. Indeed, boys were found to have higher scores on EMSs within the impaired limits domain (e.g., entitlement/grandiosity), which, in turn, have been associated with hostility, oppositional, and conduct problems (Bernstein, 2008; Calvete, Orue \& González-Diez, 2013). Alternatively, girls revealed higher scores on schemas within the disconnection and rejection (e.g. abandonment/instability and mistrust/abuse) and other- 
directedness (namely self-sacrifice) domains, concerning themes that have been found to be associated with both depression and anxiety (Calvete, Orue \& Hankin, 2013; Calvete et al., 2015).

Regarding the construct validity of the B-YSQ-A, it should be noted that it was investigated on an older subsample, who had the advantage of being more cognitively and motivationally prepared to fill out additional questionnaires in a reliable and valid way. The EMSs were found to be associated with both internalizing and externalizing symptomatology (Van Vlierberghe et al., 2010), suggesting that they are a pervasive pattern underlying general maladaptive psychological functioning (Young et al., 2003). Nevertheless, important differences were found that further sustain the divergent validity of some of the EMSs. Specifically, and assuming that the peer group has an important developmental role in adolescence, the feeling that one is not part of any group and is isolated from the rest of the world (i.e., the content of the social isolation schema), seemed to be specifically and most strongly associated with internalizing symptomatology (Van Vlierberghe \& Braet, 2007). Alternatively, thinking of oneself as entitled to more rights than those given to others, which is typical of the entitlement/grandiosity schema, associated most strongly with externalization. This same schema was also particularly associated with trait anger, which is in line with previous findings (Bernstein, 2008; Saritas \& Gençöz, 2011; Van Vlierberghe \& Braet, 2007).

Also in line with the pervasiveness of EMSs, they most strongly associated, overall, with trait anger, in comparison with state anger or anger expression. Alternatively, state anger and anger expression correlated more strongly with the mistrust/ abuse EMS in specific. It makes sense that if a person expects to be abused by others, s/he will feel and somehow express anger; in turn, if one feels and expresses anger in an inappropriate way, others are more likely to be mistreating towards oneself.

\section{Limitations}

The sole reliance on self-report instruments, which may be susceptible to social desirability or distractibility patterns of response, is one of the limitations of this work. Another has to do with it not considering exploratory measurement models, and so the hypothesis 
remains that an alternative model would be a better fit for the data. A confirmatory methodology was selected because previous results were, on the one hand conflicting and, on the other, nontheory-driven. Thus, it was considered best to test a theory-driven model that might serve the purpose of cross-cultural studies. Yet another consideration has to do with the subsamples used for construct validity and test-retest reliability being relatively small and older than the complete sample; this was due to the length of the self-report questionnaire (i.e., 90 items when administered). Finally, and considering that EMSs may be particularly prominent in clinical samples, future research should consider such samples. Namely, this could provide more evidence concerning the stability and homogeneity of EMSs, their relationships with early life histories, and their differential associations with specific psychopathologies.

Despite these limitations, the current work succeeded in proposing a valid and reliable brief measurement instrument for assessing EMSs in adolescence, both for research and clinical purposes. In the research field, the B-YSQ-A is a psychometrically solid and languageappropriate self-report instrument. In clinical settings, as with any other standardized measure, the B-YSQ-A should not be used without a careful clinical evaluation; on the contrary, clinical judgment should be exercised when analyzing its results. Evaluating the EMSs of young people may provide insight into the presence of (mal)adaptive relations with significant others, from which these schemas develop. In such cases, efforts may then be made to guide families into more beneficial and healthy interpersonal cycles that help parents better satisfy the basic emotional needs of their children (Loose, Graaf, \& Zarbock; 2013). The B-YSQ-A provides appropriate screening for the presence of EMSs since early years, thus constituting an advantage in researching, preventing mental illness, and promoting mental-health throughout the lifespan.

\section{References}

Achenbach, T. M. (1991). Integrative guide for the 1991 CBCL/4-18, YSR, and TRF profiles.

Burlington, VT: University of Vermont, Department of Psychiatry.

Bach, B., Simonsen, E., Christoffersen, P., \& Kriston, L. (2015). The Young Schema

Questionnaire 3 Short Form (YSQ-S3) Psychometric Properties and Association With 
Personality Disorders in a Danish Mixed Sample. European Journal of Psychological Assessment, 1-10. doi:10.1027/1015-5759/a000272

Bernstein, D. (2008, October). Agreement of raters in identifying schema modes from videotapes of therapy sessions. Communication presented at 3rd Annual Meeting of International Society of Schema Therapy, Coimbra, Portugal.

Calvete, E., Orue, I., \& González-Diez, Z. (2013). An examination of the structure and stability of Early Maladaptive Schemas by means of the Young Schema Questionnaire-3. European Journal of Psychological Assessment, 29, 283-290. doi:10.1027/1015$5759 / \mathrm{a} 000158$

Calvete, E., Orue, I., \& Hankin, B.L. (2013). Early maladaptive schemas and social anxiety in adolescents: The mediating role of anxious automatic thought. Journal of Anxiety Disorders, 27, 278-288. doi:10.1016/j.janxdis.2013.02.011

Calvete, E., Orue, I., \& Hankin, B.L. (2015). A longitudinal test of the vulnerability-stress model with early maladaptive schemas for depressive and social anxiety symptoms in adolescents. Journal of Psychopathology and Behavioral Assessment, 37, 85-99. doi:10.1007/s10862-014-9438-x

Chen, F. F. (2007). Sensitivity of goodness of fit indexes to lack of measurement invariance. Structural Equation Modeling, 14, 464-504. doi:10.1080/10705510701301834

Dimitrov, D. M. (2006). Comparing groups on latent variables: A structural equation modeling approach. Work (Reading, Mass.), 26, 429-36.

Fan, X.F., Miller, B.C., Park. K., Winward, B.W., Christensen, M., Grotevant, H.D., \& Tai, R.H. (2006). Exploratory study about inaccuracy and invalidity in adolescent self-report surveys. Field Methods, 18, 223-244.

Fonseca, A. C., \& Monteiro, C. M. (1999). Um inventário de problemas do comportamento para crianças e adolescentes: O Youth Self-Report de Achenbach [An inventory of behavioral problem for children and adolescents: The Youth Self-Report of Achenbach]. Psychologica, 21, 79-96. 
Gaderman, A.M., Guhn, M., \& Zumbo, B.D. (2012). Estimating ordinal reliability for likerttype and ordinal item response data: A conceptual, empirical and practical guide.

Practical Assessment, Research \& Evaluation, 17(3). Available online: http://pareonline.net/pdf/v17n3.pdf

González-Jiménez. A.J., \& Hernández-Romera, M.M. (2014). Early Maladaptive Schemas in adolescence: A quantitative study. Procedia Social and Behavioral Sciences, 132, $504-$ 508. doi:10.1016/j.sbspro.2014.04.344

Hawke, L.D., \& Provencher, M.D. (2012). The Canadian French Young Schema Questionnaire: Confirmatory factor analysis and validation in clinical and nonclinical samples. Canadian Journal of Behavioural Science, 44, (1), 40-49. doi:10.1037/a0026197

Hoffart, A., Sextton, H., Hedley, L.M., Wang, C.E., Holthe, H., Haugum, J.A., ... Holte, A. (2005). The structure of maladaptive schemas: A confirmatory factor analysis and a psychometric evaluation of factor-derived scales. Cognitive Therapy and Research, 29 (6), 627-644. doi:10.1007/s10608-005-9630-0

Hu, L., \& Bentler, P. (1999). Cutoff criteria for fit indexes in covariance structure analysis: Conventional criteria versus new alternatives. Structural Equation Modeling: A Multidisciplinary Journal, 61, 1-55. doi:10.1080/10705519909540118

Instituto Nacional de Estatística. (2011). Classificação Portuguesa das profissões 2010 [2010 Portuguese classification of professions]. Lisboa, Portugal: Instituto Nacional de Estatística.

Kriston, L., Schäfer, J., Wolf, A.V., Härter, M., \& Hölzel, L. P. (2012). The latent factor structure of Young's early maladaptive schemas: Are schemas organized into domains? Journal of Clinical Psychology, 68(6), 684-698. doi:10.1002/jclp.21846

Kriston, L., Schäfer, J., Jacob, G. A., Härter, M., \& Hölzel, L. P. (2013). Reliability and validity of the German version of the Young Schema Questionnaire - Short Form 3 (YSQ-S3). European Journal of Psychological Assessment, 29, 205-212. doi:10.1027/1015$5759 / \mathrm{a} 000143$ 
Li, C.H. (2016). Confirmatory factor analysis with ordinal data: Comparing robust maximum likelihood and diagonally weighted least squares. Behavior Research Methods, 48(3), 936-949. doi: 10.3758/s13428-015-0619-7.

Loose, C., Graaf, P., \& Zarbock, G. (2013). Schema Therapy for Children and Adolescents. N.J., USA: Wiley-Blackwell.

Maughan, B., Rowe, R., Messer, J., Goodman, R., \& Meltzer, H. (2004). Conduct disorder and oppositional defiant disorder in a national sample: Developmental epidemiology. Journal of Child Psychology and Psychiatry, 45, 609-621. doi:10.1111/j.14697610.2004.00250.x

Muris, P. (2006). Maladaptive schemas in non-clinical adolescents: Relations to perceived parental earing behaviours, big five personality factors, and psychopathological symptoms. Clinical Psychology and Psychotherapy, 13, 405-413. doi:10.1002/cpp.506

Muthén, L.K., \& Muthén, B.O. (2012). Mplus User's Guide (7th ed.), Los Angeles, CA: Muthén \& Muthén.

Pinto Gouveia, J., Rijo, D., \& Salvador, M.C. (unpublished). Questionário de Esquemas de Young [Young Schema Questionnaire]. Unpublished material

Rijkeboer, M.M., \& Boo, G.M. (2010). Early maladaptive schemas in children: Development and validation of the schema inventory for children. Journal of Behavioral Therapy \& Experimental Psychiatry, 41, 102-109. doi:10.1016/j.jbtep.2009.11.001

Rijo, D. (2009). Esquemas Mal-adaptativos precoces: Validação do conceito e dos métodos de avaliação [Early Maladaptive Schemas: Validation of the concept and evaluation methods]. Unpublished doctoral dissertation. Coimbra: University of Coimbra.

Rijo, D. (2017). O questionário de esquemas de Young (YSQ-S3) [The Young Schema Questionnaire]. In Gonçalves, M. Simões, M. R., \& Almeida, L. (Eds). Psicologia clínica e da saúde: instrumentos de avaliação [Clinical and Health Psychology: Assessment] (pp. 159-173). Lisbon: PACTOR.

RStudio Team (2015). RStudio: Integrated Development for RStudio, Inc. Boston, MA: URL http://www.rstudio.com/ 
Saritaş, D., \& Gençöz, T. (2011). Psychometric properties of "Young Schema QuestionnaireShort Form 3" in a Turkish adolescent sample. Journal of Cognitive and Behavioral Psychotherapies, 11, 83-96.

Sawyer, S.N., Afifi, R.A., Bearinger, L.H., Blakemore, S., Dick, B., Ezeh, A.C., \& Patton, G.C. (2012). Adolescence: A foundation for future health. The lancet, 379(9826), 1630-1640. doi: 10.1016/S0140-6736(12)60072-5

Silva, D.R., Campos, R., \& Prazeres, N. (1999). O Inventário de estado-traço de raiva (STAXI) e sua adaptação para a população portuguesa [The state-trait anger inventory (STAXI) and its adaptation to the Portuguese population]. Revista Portuguesa de Psicologia, 34, $55-81$.

Simons, J. \& Free, M. (2000). Development of a Children's Schema Questionnaire. Unpublished doctoral dissertation, Griffith University, Brisbane, Australia.

Shorey, R. C., Anderson, S. E.,\& Stuart,G. L. (2012). Gender differences in early maladaptive schemas in a treatment-seeking sample of alcohol-dependent adults. Substance Use and Misuse, 47, 108-116. doi:10.3109/10826084.2011.629706

Soygüt, G., Karaosmanoglu, A., \& Cakir, Z. (2009). Assessment of early maladaptive schemas: A psychometric study of the Turkish Young Schema Questionnaire-Short Form-3. Turkish Journal of Psychiatry, 20, 75-84.

Spielberger, C.D. (1988). Manual for the State-Trait Anger Expression Inventory (STAXI). Odessa, Florida: Psychological Assessment Resources.

Stallard, P. (2007). Early maladaptive schemas in children: Stability and differences between a community and a clinic referred sample. Clinical Psychology and Psychotherapy, 14 (1), 10-18. doi:10.1002/cpp.511

Stallard, P., \& Rayner, H. (2005). The development and preliminary evaluation of a Schema Questionnaire for children (SQC). Behavioural and Cognitive Psychotherapy, 33, 217224. doi:10.1017/S1352465804001912 
Van Vlierberghe, L., \& Braet, C. (2007). Dysfunctional schemas and psychopathology in referred obese adolescents. Clinical Psychology and Psychotherapy, 14, 342-351. doi:10.1002/cpp.546

Van Vlierberghe, L.V., Braet, C., Bosmans, G., Rosseel, Y. \& Bogels, S. (2010). Maladaptive schemas and psychopathology in adolescence: On the utility of Young's schema theory in youth. Cognitive Therapy and Research, 34, 316-332. doi:10.1007/s10608-009-9283-5

Waller, G., Meyer, C., \& Ohanian, V. (2001). Psychometric properties of the long and short versions of the Young Schema Questionnaire: Core beliefs among bulimic and comparison women. Cognitive Therapy and Research, 25, 137-147. doi:10.1023/A:1026487018110

Welburn, K., Coristine, M., Dagg, P., Pontefract, A., \& Jordan, S. (2002). The Schema Questionnaire - Short form: Factor analysis and relationship between schemas and symptoms. Cognitive Therapy and Research, 26 (4), 519-530. doi:10.1023/A:1016231902020

Young, J. E. (1999). Cognitive therapy for personality disorders: A schema-focused approach ( $3^{\text {rd }}$ ed.). Sarasota, FL: Professional Resource Press.

Young, J. E. (2005). Young Schema Questionnaire S3. New York: Cognitive Therapy Center of New York.

Young, J. E., \& Brown, G. (1990). Young schema questionnaire. New York: Cognitive Therapy Center of New York.

Young, J.E., Klosko, J.S., \& Weishaar, M.E. (2003). Schema Therapy: A practitioner's guide. New York: Guildford Press. 
Table 1.

Sociodemographic characteristics of the complete sample and subsamples

\begin{tabular}{lccc}
\hline & $\begin{array}{c}\text { Complete sample } \\
(\mathrm{n}=877)\end{array}$ & $\begin{array}{c}\text { Validity subsample } \\
(\mathrm{n}=146)\end{array}$ & $\begin{array}{c}\text { Stability subsample } \\
(\mathrm{n}=45)\end{array}$ \\
\hline Gender & $389(44.4)$ & $66(45.2)$ & $19(42.2)$ \\
$\quad$ Male & $488(55.6)$ & $80(54.8)$ & $26(57.8 \%)$ \\
$\quad$ Female & $14.84(1.86)$ & $16.55(1.76)$ & $17.04(0.71)$ \\
Age & $8.30(1.68)$ & $8.91(1.47)$ & $10.67(0.48)$ \\
School years completed & $0.27(0.56)$ & $0.39(0.65)$ & $0.22(0.47)$ \\
School holdbacks & & & $26(64.4)$ \\
Socioeconomic status & $597(68.1)$ & $105(71.09)$ & $15(33.3)$ \\
$\quad$ Low & $251(28.6)$ & $37(25.3)$ & $1(2.2)$ \\
$\quad$ Medium & $29(3.3)$ & $4(2.7)$ & \\
$\quad$ High & & & \\
\hline
\end{tabular}

Note: Socioeconomic status (SES) was measured by parents' profession, considering the Portuguese professions classification (Instituto Nacional de Estatística, 2010). Examples of professions in the high SES group are judges, higher education professors, or MDs; in the medium SES group are nurses, psychologists, or school teachers; and in the low SES group are farmers, cleaning staff, or undifferentiated workers. Data for gender and socioeconomic status are presented as n (\%); data for age, school years completed and school holdbacks are presented as M (SD). 
Table 2.

Fit indicators for Confirmatory Factor Analyses

\begin{tabular}{|c|c|c|c|c|c|c|}
\hline & $\chi^{2}$ & $\mathrm{df}$ & RMSEA (90\% CI) & CFI & SRMR & AIC \\
\hline \multicolumn{7}{|l|}{ YSQ } \\
\hline \multicolumn{7}{|l|}{ Complete sample } \\
\hline One-factor & 1456.96 & 3915 & $0.056(0.055 ; 0.057)$ & 0.558 & 0.075 & 255484.69 \\
\hline 18 factors & 7983.78 & 3762 & $0.036(0.035 ; 0.037)$ & 0.825 & 0.066 & 247524.03 \\
\hline Higher order model & 9536.99 & 3887 & $0.041(0.040 ; 0.042)$ & 0.765 & 0.078 & 249209.68 \\
\hline \multicolumn{7}{|l|}{ B-YSQ-A } \\
\hline \multicolumn{7}{|l|}{ Complete sample } \\
\hline One-factor & 7384.44 & 1377 & $0.071(0.069 ; 0.072)$ & 0.550 & 0.083 & 154657.15 \\
\hline 18 factors & 2412.84 & 1224 & $0.033(0.031 ; 0.035)$ & 0.911 & 0.044 & 14560.60 \\
\hline Higher order model & 3519.99 & 1349 & $0.043(0.042 ; 0.045)$ & 0.837 & 0.069 & 149718.17 \\
\hline Male participants & 1948.67 & 1224 & $0.039(0.036 ; 0.042)$ & 0.878 & 0.052 & 66448.79 \\
\hline Female participants & 2006.09 & 1224 & $0.036(0.033 ; 0.039)$ & 0.906 & 0.052 & 81803.32 \\
\hline Early adolescence & 2002.43 & 1224 & $0.040(0.037 ; 0.043)$ & 0.876 & 0.054 & 69196.29 \\
\hline Late adolescence & 1935.55 & 1224 & $0.035(0.032 ; 0.038)$ & 0.909 & 0.049 & 79246.34 \\
\hline
\end{tabular}

Note: YSQ-A = Young Schema Questionnaire for Adolescents; B-YSQ-A = Brief form of the Young Schema Questionnaire for Adolescents; $\chi^{2}$ values were always significant at $p<.001$ 
Table 3.

Loading values for the Brief form of the Young Schema Questionnaire for Adolescents

\begin{tabular}{cccccc}
\hline & $\lambda \mathrm{EMS}^{1}$ & $\lambda \mathrm{EMS}^{2}$ & $\lambda \mathrm{EMS}^{3}$ & $\lambda \mathrm{EMS}^{4}$ & $\lambda \mathrm{EMS}^{5}$ \\
\hline Abandonment/ instability $\left(\mathrm{r}^{2}=.89\right)$ & & & & & \\
Item 20 & 0.658 & 0.639 & 0.642 & 0.620 & 0.697 \\
Item 38 & 0.773 & 0.753 & 0.783 & 0.774 & 0.757 \\
Item 56 & 0.723 & 0.686 & 0.736 & 0.731 & 0.727
\end{tabular}

Mistrust/ abuse $\left(r^{2}=.88\right)$

$\begin{array}{llllll}\text { Item } 39 & 0.647 & 0.635 & 0.653 & 0.690 & 0.616 \\ \text { Item } 57 & 0.651 & 0.667 & 0.628 & 0.609 & 0.683 \\ \text { Item 75 } & 0.587 & 0.581 & 0.591 & 0.553 & 0.614\end{array}$

Emotional deprivation $\left(\mathrm{r}^{2}=.88\right)$

$\begin{array}{llllll}\text { Item 19 } & 0.602 & 0.532 & 0.656 & 0.613 & 0.611 \\ \text { Item 55 } & 0.809 & 0.702 & 0.872 & 0.798 & 0.813 \\ \text { Item 73 } & 0.822 & 0.782 & 0.853 & 0.841 & 0.808\end{array}$

Defectiveness/ shame $\left(\mathrm{r}^{2}=.90\right)$

$\begin{array}{llllll}\text { Item 5 } & 0.653 & 0.622 & 0.696 & 0.610 & 0.715 \\ \text { Item 23 } & 0.758 & 0.693 & 0.812 & 0.752 & 0.774 \\ \text { Item 59 } & 0.781 & 0.785 & 0.769 & 0.784 & 0.766\end{array}$

Social isolation/ alienation $\left(\mathrm{r}^{2}=.92\right)$

$\begin{array}{llllll}\text { Item } 22 & 0.755 & 0.700 & 0.793 & 0.774 & 0.734 \\ \text { Item } 40 & 0.812 & 0.712 & 0.846 & 0.638 & 0.788 \\ \text { Item } 58 & 0.716 & 0.776 & 0.718 & 0.807 & 0.827\end{array}$

Dependence/ incompetence $\left(\mathrm{r}^{2}=.81\right)$

$\begin{array}{llllll}\text { Item 25 } & 0.525 & 0.574 & 0.496 & 0.437 & 0.608 \\ \text { Item } 43 & 0.538 & 0.510 & 0.673 & 0.489 & 0.582 \\ \text { Item 79 } & 0.689 & 0.649 & 0.734 & 0.673 & 0.698\end{array}$

Vulnerability to harm or illness $\left(r^{2}=.86\right)$

$\begin{array}{llllll}\text { Item 26 } & 0.561 & 0.570 & 0.562 & 0.560 & 0.560 \\ \text { Item 62 } & 0.674 & 0.637 & 0.708 & 0.673 & 0.677 \\ \text { Item 80 } & 0.655 & 0.711 & 0.606 & 0.672 & 0.637\end{array}$

Enmeshment/ undeveloped self $\left(r^{2}=.82\right)$

$\begin{array}{llllll}\text { Item } 27 & 0.688 & 0.688 & 0.687 & 0.647 & 0.722 \\ \text { Item } 45 & 0.729 & 0.685 & 0.762 & 0.726 & 0.730 \\ \text { Item } 81 & 0.783 & 0.742 & 0.816 & 0.778 & 0.779\end{array}$

Failure $\left(r^{2}=.90\right)$

$\begin{array}{llllll}\text { Item } 42 & 0.781 & 0.694 & 0.839 & 0.801 & 0.764 \\ \text { Item 60 } & 0.821 & 0.770 & 0.854 & 0.812 & 0.822 \\ \text { Item 78 } & 0.792 & 0.771 & 0.803 & 0.771 & 0.815\end{array}$

Entitlement/ grandiosity $\left(r^{2}=.77\right)$ 


$\begin{array}{llllll}\text { Item 14 } & 0.518 & 0.513 & 0.583 & 0.453 & 0.546 \\ \text { Item 32 } & 0.628 & 0.715 & 0.488 & 0.549 & 0.671 \\ \text { Item 68 } & 0.554 & 0.679 & 0.376 & 0.476 & 0.622\end{array}$

Insufficient self-control and/or self-discipline $\left(r^{2}=.86\right)$

$\begin{array}{llllll}\text { Item } 15 & 0.569 & 0.462 & 0.651 & 0.540 & 0.593 \\ \text { Item } 51 & 0.624 & 0.636 & 0.580 & 0.576 & 0.647 \\ \text { Item 87 } & 0.628 & 0.642 & 0.626 & 0.620 & 0.650\end{array}$

Subjugation $\left(\mathrm{r}^{2}=.78\right)$

$\begin{array}{llllll}\text { Item } 28 & 0.645 & 0.557 & 0.787 & 0.705 & 0.635 \\ \text { Item } 46 & 0.625 & 0.585 & 0.756 & 0.695 & 0.612 \\ \text { Item } 82 & 0.588 & 0.697 & 0.439 & 0.504 & 0.608\end{array}$

Self-sacrifice $\left(r^{2}=.84\right)$

$\begin{array}{llllll}\text { Item 11 } & 0.479 & 0.455 & 0.485 & 0.429 & 0.526 \\ \text { Item 29 } & 0.638 & 0.585 & 0.672 & 0.604 & 0.657 \\ \text { Item 83 } & 0.726 & 0.697 & 0.736 & 0.660 & 0.780\end{array}$

Approval-seeking/ recognition seeking $\left(\mathrm{r}^{2}=.84\right)$

$\begin{array}{llllll}\text { Item 34 } & 0.618 & 0.612 & 0.601 & 0.561 & 0.657 \\ \text { Item 52 } & 0.651 & 0.663 & 0.678 & 0.664 & 0.643 \\ \text { Item 88 } & 0.713 & 0.709 & 0.721 & 0.694 & 0.729\end{array}$

Negativity/ pessimism $\left(\mathrm{r}^{2}=.85\right)$

$\begin{array}{llllll}\text { Item } 17 & 0.661 & 0.637 & 0.667 & 0.623 & 0.711 \\ \text { Item 35 } & 0.684 & 0.698 & 0.675 & 0.709 & 0.682 \\ \text { Item 53 } & 0.754 & 0.743 & 0.773 & 0.803 & 0.704\end{array}$

Emotional inhibition $\left(\mathrm{r}^{2}=.88\right)$

$\begin{array}{llllll}\text { Item } 12 & 0.674 & 0.567 & 0.723 & 0.610 & 0.720 \\ \text { Item } 30 & 0.733 & 0.678 & 0.751 & 0.700 & 0.748 \\ \text { Item } 84 & 0.649 & 0.719 & 0.620 & 0.637 & 0.678\end{array}$

Unrelenting standards/ hyper-criticalness $\left(\mathrm{r}^{2}=.81\right)$

$\begin{array}{llllll}\text { Item } 13 & 0.714 & 0.683 & 0.744 & 0.726 & 0.698 \\ \text { Item } 31 & 0.713 & 0.687 & 0.711 & 0.713 & 0.715 \\ \text { Item } 85 & 0.564 & 0.547 & 0.576 & 0.585 & 0.541\end{array}$

Punitiveness $\left(\mathrm{r}^{2}=.88\right)$

$\begin{array}{llllll}\text { Item 18 } & 0.722 & 0.693 & 0.742 & 0.674 & 0.777 \\ \text { Item 54 } & 0.752 & 0.704 & 0.790 & 0.774 & 0.728 \\ \text { Item 72 } & 0.708 & 0.712 & 0.708 & 0.726 & 0.702\end{array}$

Note: The $\mathrm{r}^{2}$ values refer to linear regression analyses entering the 3 -item measure as sole predictor of its 5-item counterpart.

${ }^{1}$ Complete sample $(\mathrm{n}=877),{ }^{2}$ Male sample $(\mathrm{n}=389),{ }^{3}$ Female sample $(\mathrm{n}=488),{ }^{4}$ Early adolescence sample $(n=407),{ }^{5}$ Late adolescence sample $(n=476)$ 
Table 4.

Internal consistency and descriptive analyses results for the Brief form of the Young Schema Questionnaire for Adolescents

\begin{tabular}{|c|c|c|c|c|c|c|c|}
\hline & $\begin{array}{c}\text { Internal } \\
\text { consistency }\end{array}$ & $\begin{array}{l}\text { Temporal } \\
\text { stability }\end{array}$ & $\begin{array}{l}\text { Mean } \\
(\mathrm{SD})^{1}\end{array}$ & $\begin{array}{l}\text { Mean } \\
(\mathrm{SD})^{2}\end{array}$ & $\begin{array}{l}\text { Mean } \\
(\mathrm{SD})^{3}\end{array}$ & LMC & $\begin{array}{c}\text { Effect } \\
\text { size }\end{array}$ \\
\hline Abandonment/ instability & .80 & $.716^{* * *}$ & $3.64(1.43)$ & $3.31(1.38)$ & $3.91(1.41)$ & $.464^{* * * *}$ & -.43 \\
\hline Mistrust/ abuse & 67 & $.645^{* * * *}$ & $2.67(1.19)$ & $2.55(1.14)$ & $2.78(1.22)$ & $.243^{* *}$ & -.19 \\
\hline Emotional deprivation & .87 & $.441^{* * *}$ & $1.75(1.04)$ & $1.79(0.97)$ & $1.71(1.10)$ & $-.051^{\mathrm{ns}}$ & .07 \\
\hline Defectiveness/ shame & .84 & $.586^{* * *}$ & $1.72(0.96)$ & $1.79(0.97)$ & $1.67(0.95)$ & $-.136^{\mathrm{ns}}$ & .12 \\
\hline Social isolation/ alienation & .88 & $.708^{* * * *}$ & $1.73(1.02)$ & $1.79(1.08)$ & $1.69(1.03)$ & $-.100^{\mathrm{ns}}$ & .09 \\
\hline Dependence/ incompetence & .72 & $.406^{* * * *}$ & $1.66(0.74)$ & $1.71(0.75)$ & $1.62(0.73)$ & $-.122^{\mathrm{ns}}$ & .12 \\
\hline Vulnerability to harm or illness & .72 & $.499^{* * * *}$ & $2.71(1.26)$ & $2.63(1.27)$ & $2.78(1.25)$ & $.157^{\mathrm{ns}}$ & -.12 \\
\hline Enmeshment/ undeveloped self & .82 & $.591^{* * *}$ & $2.84(1.32)$ & $2.79(1.25)$ & $2.87(1.37)$ & $.047^{\mathrm{ns}}$ & -.06 \\
\hline Failure & .88 & $.572^{* * *}$ & $2.10(1.15)$ & $2.05(1.06)$ & $2.14(1.23)$ & $.077^{\mathrm{ns}}$ & -.08 \\
\hline Entitlement/ grandiosity & .69 & $.711^{* * *}$ & $1.81(0.83)$ & $1.91(0.91)$ & $1.72(0.76)$ & $-.543^{* *}$ & .29 \\
\hline $\begin{array}{l}\text { Insufficient self-control and/or } \\
\text { self-discipline }\end{array}$ & .70 & $.639^{* * *}$ & $2.21(1.01)$ & $2.37(1.03)$ & $2.08(0.98)$ & $-.342^{* * *}$ & .29 \\
\hline Subjugation & .74 & $.482^{* * * *}$ & $1.87(0.88)$ & $1.92(0.86)$ & $1.83(0.89)$ & $-.090^{\mathrm{ns}}$ & .10 \\
\hline Self-sacrifice & .67 & $.734^{* * *}$ & $2.75(1.07)$ & $2.58(1.01)$ & $2.88(1.11)$ & $.335^{* * *}$ & -.28 \\
\hline $\begin{array}{l}\text { Approval-seeking/ recognition } \\
\text { seeking }\end{array}$ & .75 & $.666^{* * *}$ & $2.39(1.13)$ & $2.50(1.13)$ & $2.31(1.12)$ & $-.185^{*}$ & .17 \\
\hline Negativity/ pessimism & .79 & $.774^{* * *}$ & $2.59(1.21)$ & $2.53(1.18)$ & $2.64(1.22)$ & $.083^{\mathrm{ns}}$ & -.09 \\
\hline Emotional inhibition & .77 & $.757^{* * * *}$ & $2.59(1.24)$ & $2.65(1.18)$ & $2.54(1.29)$ & $-.114^{\mathrm{ns}}$ & .09 \\
\hline $\begin{array}{l}\text { Unrelenting standards/ hyper- } \\
\text { criticalness }\end{array}$ & .75 & $.566^{* * *}$ & $2.69(1.20)$ & $2.87(1.21)$ & $2.54(1.19)$ & $-.334^{* * *}$ & .27 \\
\hline Punitiveness & .80 & $.711^{* * * *}$ & $1.65(0.74)$ & $1.72(0.75)$ & $1.60(0.73)$ & $-.171^{*}$ & .16 \\
\hline
\end{tabular}

Note: Internal consistency was based on the ordinal Guttman's Lambda-2; Temporal stability is based on spearman correlation coefficient of the scores of the same measure across two time points. LMC = Latent mean comparison.

${ }^{1}$ Complete sample $(n=877),{ }^{2}$ Male sample $(n=389),{ }^{3}$ Female sample $(n=488)$

${ }^{* * *} \mathrm{p}<.001 ;{ }^{* *} \mathrm{p}<.01 ;{ }^{*} \mathrm{p}<.05 ;{ }^{\mathrm{ns}}=$ non-significant 
THE BRIEF FORM OF THE YOUNG SCHEMA QUESTIONNAIRE FOR ADOLESCENTS

Table 5 .

Correlation values between the Brief form of the Young Schema Questionnaire and relevant external variables

\begin{tabular}{|c|c|c|c|c|c|c|c|c|c|c|c|c|c|c|c|c|c|c|}
\hline & \multicolumn{18}{|c|}{ Early maladaptive schemas } \\
\hline & $\mathrm{AB}$ & MA & ED & DS & SI & DI & $\mathrm{VH}$ & EM & FA & ET & IS & SB & SS & AS & NP & EI & US & $\mathrm{PU}$ \\
\hline \multicolumn{19}{|l|}{ Youth Self Report } \\
\hline Internalizing & $.19^{*}$ & $.39^{* * *}$ & $.32^{* * *}$ & $.39^{* * *}$ & $.46^{* * *}$ & $.32^{* * *}$ & $.32^{* * *}$ & $-.04^{\mathrm{ns}}$ & $.25^{* *}$ & $.16^{\mathrm{ns}}$ & $.30^{* * *}$ & $.39^{* * *}$ & $.25^{* *}$ & $.22^{* *}$ & $.31^{* * *}$ & $.26^{* *}$ & $.06^{\mathrm{ns}}$ & $.17^{*}$ \\
\hline Externalizing & $.07^{\mathrm{ns}}$ & $.23^{* *}$ & $.15^{\mathrm{ns}}$ & $.28^{* *}$ & $.26^{* *}$ & $.19^{*}$ & $.27^{*}$ & $-.04^{\mathrm{ns}}$ & $.12^{\mathrm{ns}}$ & $.30^{* * *}$ & $.27^{* *}$ & $.30^{* * * *}$ & $.19^{\mathrm{ns}}$ & $.26^{* *}$ & $.21^{*}$ & $.13^{\mathrm{ns}}$ & $.20^{*}$ & $.14^{\mathrm{ns}}$ \\
\hline \multicolumn{19}{|l|}{ STAXI } \\
\hline State Anger & $.12^{\mathrm{ns}}$ & $.36^{* * *}$ & $.27^{* *}$ & $.23^{* *}$ & $.28^{* *}$ & $.08^{\mathrm{ns}}$ & $.23^{* *}$ & $-.056^{\mathrm{ns}}$ & $.09^{\mathrm{ns}}$ & $.17^{*}$ & $.20^{*}$ & $.32^{* * *}$ & $.13^{\mathrm{ns}}$ & $.29^{* * *}$ & $.29^{* * *}$ & $-.16^{\mathrm{ns}}$ & $.15^{\mathrm{ns}}$ & $.21^{*}$ \\
\hline Trait anger & $.16^{\mathrm{ns}}$ & $.40^{* * *}$ & $.16^{\mathrm{ns}}$ & $.28^{* *}$ & $.16^{\mathrm{ns}}$ & $.17^{*}$ & $.20^{*}$ & $-.00^{\mathrm{ns}}$ & $-.03^{\mathrm{ns}}$ & $.43^{* * *}$ & $.31^{* * *}$ & $.29^{* * *}$ & $.19^{*}$ & $.37^{* * *}$ & $.39^{* * *}$ & $.24^{* *}$ & $.30^{* * *}$ & $.16^{*}$ \\
\hline Anger expression & $.10^{\mathrm{ns}}$ & $.32^{* * *}$ & $.23^{* *}$ & $.27^{* *}$ & $.14^{\mathrm{ns}}$ & $.08^{\mathrm{ns}}$ & $.06^{\mathrm{ns}}$ & $-.01^{\mathrm{ns}}$ & $.07^{\mathrm{ns}}$ & $.01^{\mathrm{ns}}$ & $.18^{*}$ & $.28^{* *}$ & $.25^{* *}$ & $.21^{*}$ & $.19^{*}$ & $.27^{* *}$ & $.18^{*}$ & $.15^{\mathrm{ns}}$ \\
\hline
\end{tabular}

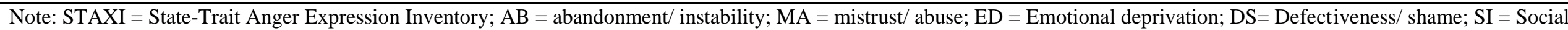

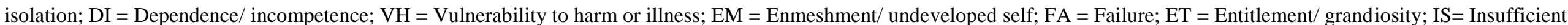

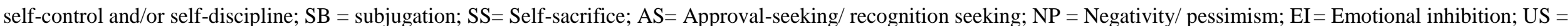
Unrelenting standards/ hyper-criticalness; PU= Punitiveness.

${ }^{* * *} \mathrm{p}<.001 ;{ }^{* *} \mathrm{p}<.01 ;{ }^{*} \mathrm{p}<.05 ;{ }^{\mathrm{ns}}=$ non-significant 
Supplementary material 1.

Themes of Young's Early Maladaptive Schemas and Domains (adapted from Young et al., 2003)

Disconnection and Rejection

1.Abandonment/Instability

Significant others will be unavailable or unreliable in their support and connection.

2.Mistrust/Abuse

Other people will intentionally hurt, abuse, manipulate or take advantage of one.

3.Emotional Deprivation

The expectation that one's emotional support needs will not be met by others.

4.Defectiveness/Shame

The feeling that one is bad, defective or inferior.

5.Social Isolation/

Alienation

The feeling that one is isolated, different from other people, not being a part of a group.

Impaired Autonomy and Performance

6.Dependence/Incompetence

7.Vulnerability to Harm or Illness

8.Enmeshment/Undeveloped

Self

9.Failure

Impaired Limits

10. Entitlement/Grandiosity

11. Insufficient selfcontrol/discipline

Other-Directedness

12.Subjugation

13. Self-Sacrifice

14. Approval

Seeking/Recognition

Over vigilance and Inhibition

15. Negativity/Pessimism

16. Emotional Inhibition

17.Unrelenting Standards/

Hyper criticalness

18. Punitiveness
One cannot handle daily responsibilities without be helped from others. Fear that catastrophic events will happen and one cannot prevent it or cope with it.

Excessive emotional involvement and closeness with significant others development.

Sense of failure; will eventually fail in life.

Sense of superiority and deserves special privileges.

Difficulties with perseverance and delayed gratification.

Excessive surrendering of control to others in order to avoid feared consequences.

Excessive focus on taking care of others instead of self.

An excessive emphasis on achieving the attention, approval, and recognition of others.

High focus on the negative aspects of life.

Inhibition in expression of emotions and spontaneity.

High personal standards of behavior and performance, usually to avoid criticism.

One deserves to be punished harshly for making mistakes. 
Supplementary material

Item loading, inter-item and corrected item-total correlations, and internal consistency values if item deleted for the Young Schema Questionnaire for Adolescents

\begin{tabular}{|c|c|c|c|c|}
\hline & $\lambda \mathrm{EMS}^{1}$ & $\begin{array}{l}\text { Inter- } \\
\text { item }\end{array}$ & $\begin{array}{l}\text { Item- } \\
\text { total }\end{array}$ & $\begin{array}{c}\text { IC if item } \\
\text { deleted }\end{array}$ \\
\hline \multicolumn{5}{|l|}{ Abandonment/ instability } \\
\hline Item $2^{\mathrm{a}}$ & .567 & .366 & .485 & .756 \\
\hline Item 20 & .619 & .393 & .534 & .740 \\
\hline Item 38 & .741 & .467 & .652 & .697 \\
\hline Item 56 & .790 & .461 & .639 & .702 \\
\hline Item $74^{\mathrm{a}}$ & .561 & .339 & .442 & .768 \\
\hline \multicolumn{5}{|l|}{ Mistrust/ abuse } \\
\hline Item $3^{\mathrm{a}}$ & .522 & .317 & 0.436 & 0.703 \\
\hline Item $21^{\mathrm{a}}$ & .589 & .331 & 0.456 & 0.693 \\
\hline Item 39 & .629 & .345 & 0.479 & 0.686 \\
\hline Item 57 & .647 & .398 & 0.572 & 0.647 \\
\hline Item 75 & .574 & .358 & 0.508 & 0.675 \\
\hline \multicolumn{5}{|l|}{ Emotional deprivation } \\
\hline Item $1^{\mathrm{a}}$ & .519 & 0.382 & .476 & .785 \\
\hline Item 19 & .600 & 0.439 & .559 & .762 \\
\hline Item $37^{\mathrm{a}}$ & .677 & 0.401 & .522 & .788 \\
\hline Item 55 & .797 & 0.523 & .705 & .709 \\
\hline Item 73 & .774 & 0.502 & .675 & .726 \\
\hline \multicolumn{5}{|l|}{ Defectiveness/ shame } \\
\hline Item 5 & .632 & .439 & .567 & .783 \\
\hline Item 23 & .732 & .510 & .677 & .748 \\
\hline Item $41^{\mathrm{a}}$ & .612 & .404 & .517 & .796 \\
\hline Item 59 & .762 & .509 & .676 & .749 \\
\hline Item $77^{\mathrm{a}}$ & .673 & .436 & .562 & .783 \\
\hline \multicolumn{5}{|l|}{ Social isolation/ alienation } \\
\hline Item $4^{\mathrm{a}}$ & .652 & .490 & .594 & .841 \\
\hline Item 22 & .752 & .551 & .683 & .819 \\
\hline Item 40 & .723 & .533 & .658 & .825 \\
\hline Item 58 & .814 & .587 & .739 & .805 \\
\hline Item $76^{\mathrm{a}}$ & .739 & .538 & .665 & .823 \\
\hline \multicolumn{5}{|l|}{ Dependence/ incompetence } \\
\hline Item $7^{\mathrm{a}}$ & .465 & .294 & .411 & .646 \\
\hline Item 25 & .525 & .333 & .480 & .616 \\
\hline Item 43 & .527 & .330 & .477 & .623 \\
\hline
\end{tabular}


THE BRIEF FORM OF THE YOUNG SCHEMA QUESTIONNAIRE FOR ADOLESCENTS

$\begin{array}{lrrrr}\text { Item } 61^{\mathrm{a}} & .555 & .270 & .384 & .657 \\ \text { Item } 79 & .673 & .323 & .466 & .619\end{array}$

Vulnerability to harm or illness

$\begin{array}{lrrrr}\text { Item } 8^{\mathrm{a}} & .618 & .316 & .439 & .671 \\ \text { Item } 26 & .567 & .632 & .520 & .640 \\ \text { Item } 44^{\mathrm{a}} & .437 & .260 & .363 & .700 \\ \text { Item } 62 & .631 & .323 & .463 & .663 \\ \text { Item } 80 & .604 & .380 & .555 & .620\end{array}$

Enmeshment/ undeveloped self

$\begin{array}{lrrrr}\text { Item } 9^{\mathrm{a}} & .513 & .299 & .441 & .621 \\ \text { Item } 27 & .677 & .341 & .524 & .581 \\ \text { Item } 45 & .707 & .361 & .555 & .566 \\ \text { Item } 63^{\mathrm{a}} & .071 & .044 & .058 & .762 \\ \text { Item } 81 & .800 & .389 & .617 & .544\end{array}$

Failure

$\begin{array}{lrrrr}\text { Item } 6^{\mathrm{a}} & .648 & .485 & .589 & .838 \\ \text { Item } 24^{\mathrm{a}} & .666 & .487 & .593 & .839 \\ \text { Item } 42 & .770 & .551 & .690 & .812 \\ \text { Item } 60 & .817 & .587 & .744 & .798 \\ \text { Item } 78 & .768 & .558 & .701 & .809\end{array}$

Entitlement/ grandiosity

Item 14
Item 32
Item $50^{a}$
Item 68
Item $86^{\text {a }}$

$\begin{array}{llll}.524 & .257 \quad .597 & .544\end{array}$

$\begin{array}{llll}.563 & .522 & .471 \quad .520\end{array}$

$\begin{array}{llll}.479 \quad .606 & .312 \quad .67\end{array}$

$\begin{array}{llll}.491 & .274 \quad .565 & .562\end{array}$

$\begin{array}{llll}.522 & .521 \quad .350 \quad .568\end{array}$

Insufficient self-control and/or self-discipline

$\begin{array}{lrrrr}\text { Item } 15 & .595 & .373 & .525 & .673 \\ \text { Item } 33^{\mathrm{a}} & .587 & .348 & .478 & .690 \\ \text { Item } 51 & .622 & .353 & .490 & .685 \\ \text { Item } 69^{\mathrm{a}} & .537 & .335 & .467 & .695 \\ \text { Item } 87 & .636 & .367 & .511 & .680\end{array}$

Subjugation

Item $10^{\mathrm{a}}$
Item 28
Item 46
Item $64^{\mathrm{a}}$
Item 82

Self-sacrifice

Item 11

$\begin{array}{rrrr}.331 & .146 & .210 & .676 \\ .598 & .328 & .458 & .518 \\ .583 & .324 & .468 & .524 \\ .557 & .281 & .403 & .549 \\ .598 & .275 & .408 & .539\end{array}$

$\begin{array}{llll}.510 & .628 & .407 \quad 644\end{array}$


THE BRIEF FORM OF THE YOUNG SCHEMA QUESTIONNAIRE FOR ADOLESCENTS

$\begin{array}{lllll}\text { Item } 29 & .598 & .346 & .521 & .593 \\ {\text { Item } 47^{\mathrm{a}}}^{\text {Item } 65^{\mathrm{a}}} & .505 & .248 & .352 & .666 \\ \text { Item } 83 & .496 & .270 & .387 & .654 \\ & .657 & .347 & .519 & .592\end{array}$

Approval-seeking/ recognition seeking

$\begin{array}{lllll}\text { Item } 16^{\mathrm{a}} & .481 & .303 & .413 & .704 \\ \text { Item } 34 & .655 & .389 & .553 & .650 \\ \text { Item } 52 & .613 & .329 & .453 & .691 \\ \text { Item } 70^{\mathrm{a}} & .495 & .318 & .438 & .701 \\ \text { Item } 88 & .717 & .407 & .587 & .641\end{array}$

Negativity/ pessimism

$\begin{array}{lllll}\text { Item } 17 & .621 & .429 & .576 & .724 \\ \text { Item } 35 & .610 & .426 & .574 & .727 \\ \text { Item } 53 & .707 & .448 & .609 & .714 \\ \text { Item } 71^{\text {a }} & .682 & .397 & .527 & .741 \\ \text { Item } 89^{\text {a }} & .582 & .354 & .231 & .763\end{array}$

Emotional inhibition

$\begin{array}{lllll}\text { Item } 12 & .645 & .428 & .586 & .716 \\ \text { Item } 30 & .687 & .436 & .600 & .711 \\ \text { Item } 48^{\mathrm{a}} & .583 & .337 & .441 & .764 \\ \text { Item } 66^{\mathrm{a}} & .613 & .397 & .531 & .736 \\ \text { Item } 84 & .666 & .421 & .569 & .724\end{array}$

Unrelenting standards/ hyper criticalness

$\begin{array}{lllll}\text { Item } 13 & .614 & .314 & .450 & .655 \\ \text { Item } 31 & .695 & .381 & .560 & .605 \\ \text { Item } 49^{\text {a }} & .507 & .285 & .400 & .679 \\ \text { Item } 67^{\text {a }} & .432 & .259 & .359 & .693 \\ \text { Item } 85 & .612 & .362 & .529 & .625\end{array}$

Punitiveness

$\begin{array}{lllll}\text { Item } 18 & .710 & .411 & .604 & .629 \\ \text { Item } 36^{\mathrm{a}} & .505 & .269 & .383 & .727 \\ \text { Item } 54 & .743 & .414 & .616 & .623 \\ \text { Item } 72 & .691 & .394 & .585 & .638 \\ \text { Item } 90^{\mathrm{a}} & .332 & .200 & .262 & .747\end{array}$

Note: this analyses included de complete sample $(\mathrm{n}=877)$.

${ }^{a}$ Excluded from the Brief form of the Young Schema Questionnaire for Adolescents 